\title{
The systemic inflammation-based Glasgow Prognostic Score as a powerful prognostic factor in patients with upper tract urothelial carcinoma
}

\author{
Teruo Inamoto${ }^{1}$, Hideyasu Matsuyama², Shigeru Sakano ${ }^{2}$ Naokazu Ibuki $^{1}$, \\ Kiyoshi Takaharaㄹ, Kazumasa Komura ${ }^{1}$, Tomoaki Takai ${ }^{1}$, Takuya Tsujino ${ }^{1}$, Yuki \\ Yoshikawa $^{1}$, Koichiro Minami ${ }^{1}$, Kazuhiro Nagao ${ }^{2}$, Ryo Inoue ${ }^{2}$ and Haruhito Azuma ${ }^{1}$ \\ ${ }^{1}$ Department of Urology, Osaka Medical College, Osaka, Japan \\ ${ }^{2}$ Department of Urology, Graduate School of Medicine, Yamaguchi University, Ube, Japan \\ Correspondence to: Teruo Inamoto, email: tinamoto@osaka-med.ac.jp
}

Keywords: Glasgow Prognostic Score; upper tract urothelial carcinoma; prognosis

Received: June 27, 2017 Accepted: October 30, $2017 \quad$ Published: November 23, 2017

Copyright: Inamoto et al. This is an open-access article distributed under the terms of the Creative Commons Attribution License 3.0 (CC BY 3.0), which permits unrestricted use, distribution, and reproduction in any medium, provided the original author and source are credited.

\section{ABSTRACT}

Introduction and Objective: The combination of C-reactive protein and albumin, the Glasgow Prognostic Score (GPS), had independent prognostic value in patients with varying cancers, except for upper tract urothelial carcinoma (UTUC). The aim of this study was to describe the relationship between GPS and survival in patients with UTUC after adjustment for other prognostic factors.

Materials and Methods: We queried 2 UTUC databases. Retrospective clinical series on patients with localized UTUC managed by nephroureterectomy with bladder cuff, for whom data from the Yamaguchi Uro-Oncology Group and Osaka Medical College registry, including age, presence of bladder cancer, pT stage, lymphovascular invasion, C-reactive protein (CRP) and albumin, were analyzed. The GPS was constructed by combining CRP and albumin. Cancer specific survival (CSS) and overall survival (OS) and relative excess risk of death were estimated by GPS categories after adjusting for gender, age, ECOG performance status (PS), grade, and lymphovascular invasion (LVI).

Results: Seven hundred and twenty four UTUC patients were identified. Our final cohort included 574 patients; of these, $29.2 \%$ died during a maximum follow up of 16.7 years. The estimated mean 10 -year CSS of patients with GPS of scre-0, -1 , and -2 was 99.5, 95.1, and 75.9 months, respectively. Patients with GPS of score-2 had poorest 10-year estimated mean OS of 67.6 months (57.2-77.9). Raised GPS also had a significant association with excess risk of cancer death at 10 years (GPS 2: Relative Excess Risk $=1.74,95 \%$ CI 1.20-2.54) after adjusting for gender, patients' age, ECOG PS, and tumor focality. C-index of GPS both for CSS and OS were superior to patients' age and tumor focality, and comparable to grade.

Conclusions: The GPS is an independent prognostic factor for CSS and OS after surgery with curative intent for localized UTUC. It significantly increases the accuracy of established prognostic factors. The GPS may provide a meaningful adjunct for patient counseling and clinical trial design.

\section{INTRODUCTION}

The knowledge of treatment sequence in daily clinical practice is important for an optimal treatment of upper tract urothelial carcinoma (UTUC). UTUC is uncommon with roughly 3000 cases diagnosed in the United States in 2007, compared to approximately 67000 cases of urothelial carcinoma of the bladder [1]. UTUC accounts for approximately $10 \%$ of cancers arising from the kidney and less than $5 \%$ of all urothelial malignancies. 
Several risk factors for developing UTUC have been reported, including delay in radical nephroureterectomy [2] and tumor necrosis [3]. Also, a history of bladder cancer prior to UTUC resection and upper tract tumor multifocality are frequently reported clinical risk factors $[4,5]$. Predominantly because of the rarity of the disease, there is limited data to guide clinicians in decision making which consists mostly of small retrospective studies and expert opinion. Candidate pathological predictors, such as E-cadherin, are helpful for improving patient risk stratification $[4,6]$. The identification of factors that allow accurate risk stratification of UTUC patients in terms of patients' survival is emerging, and the area of defining new prognostic markers is of active interest. An unresolved question is the relationship to data from daily clinical practice. This question is becoming valuable in the light of the desire to evaluate the performance of curative surgery for UTUC in daily clinical practice. Prognostic markers in daily practice, including patients' body composition, age, gender, blood test results, and so on, may offer the opportunity for easily, and reproducible measurement before operation compared to conventional clinicopathological characteristics. The ability to predict which patients will exacerbate while receiving curative surgery would be of great help for clinicians to make adjuvant chemotherapy worthwhile. Previous studies have found that neutrophil-lymphocyte ratio $[7,8]$, postoperative platelet count [9] from blood test results were predictive of survival in patients with UTUC, but no study has ever assessed the prognostic impact of the Glasgow Prognostic Score (GPS). GPS consists of CRP and albumin as follows; patients with both an elevated CRP level $(>1.0 \mathrm{mg} / \mathrm{dl})$ and hypoalbuminemia $(<3.5 \mathrm{~g} /$ dl) are allocated a score of 2, patients with only one of these biochemical abnormalities are allocated a score of 1 , and patients with neither of these abnormalities are allocated a score of 0 . Given the prognostic role of GPS in varying malignancies, including non-small cell lung cancer [10], gastric cancer [11], colorectal liver metastases [12], esophageal cancer [13], plus deep relationship of C-reactive protein in survival of patients with UTUC $[14-16,17]$, we attempted to verify the prognostic power of the systemic inflammation-based GPS for patients with UTUC with large data across a wide range of disease. In this study we investigated the characteristics of UTUC patients in different GPS groups, and disease risk by GPS, and whether GPS score adjusted for gender, age, ECOG PS, grade, and LVI, has an impact on survival.

\section{MATERIALS AND METHODS}

\section{Study design and population}

Two UTUC databases from the Yamaguchi UroOncology Group [18] and Osaka Medical College registry [19] were combined which include retrospective clinical series on patients with localized UTUC managed by nephroureterectomy with bladder cuff. Two cohorts are approved by the IRB. Of the 724 patients screened for the study, 574 patients were included in the analysis. Synchronous metastatic disease was excluded by chest x-ray, abdominal ultrasonography and computed tomography (CT) of the abdomen and pelvis. No patient had invasive bladder tumor at the time of nephroureterectomy. Previously, open radical nephroureterectomy with open excision of the distal ureter with a bladder cuff was performed to dissect the kidney with the entire length of the ureter and adjacent segment of the bladder cuff. From June 2003 to current, the approach we use is a conventional four-trocar nephrectomy. The hilar and regional lymph nodes adjacent to the ipsilateral great vessel, if possible, were resected. We have measured the CRP and albumin pre-operatively, to be used for the definition of GPS.

\section{Statistical methods}

CSS and OS, as functions of age (discreet and continuous) were evaluated. Patients are followed until death or withdrawal from the study. An event for OS included all deaths within the cohort under investigation, and did not separate those due to the disease of interest from those due to other causes. The Kaplan-Meier method was used to estimate the survival rate and log-rank test was used to compare it among the four age cohorts. Univariate and multivariate analyses were carried out using Cox proportional hazards regression to identify outcome-related factors, after adjustment for categorical (ender, tumor focality, ECOG PS, grade, and pT stage) and continuous variables (age). In precise, we conducted analyses with gender (categorical), age (continuous), tumor focality (unifocal/ multifocal), ECOG PS (0/ 1/ 2/ $3)$, grade $(1 / 2 / 3)$, and pT stage (pT1/pT2/pT3/pT4). The level of statistical significance was set at $p<0.05$.

\section{RESULTS}

The baseline patient characteristics are shown in Table 1. A total of 574 subjects were identified, 68.8\% males with a mean age of 71 years. $96.5 \%$ of patients had ECOG PS of 1 or 0 . In this cohort, pathological diagnosis was pT1, pT2, pT3 and pT4 in 29.6\%, 28.0, 40.1\% and $2.3 \%$ of patients, respectively, with $42.4 \%$ of all patients had advanced disease ( $\geq$ T3N0M0). Tumor focality was unifocal in $81.4 \%$ of cases $(n=467)$, multifocal in $18.6 \%$ $(n=107)$. The relationships between an increasing GPS and patient-related factors are shown in Table 2. There was significant difference in histological pT classification, grade, and LVI between both groups $(p<0.05)$. GPS score 0 patients presented with lower grade, lower pT stage, and larger negative LVI numbers. In 332 patients with score 0 ; $136(41.0 \%)$ were pT1, $88(26.5 \%)$ were pT2, $104(31.3 \%)$ 


\begin{tabular}{|c|c|c|c|}
\hline & & Number & $\%$ \\
\hline \multirow[t]{2}{*}{ Gender } & Male & 395 & $68.8 \%$ \\
\hline & Female & 179 & $31.2 \%$ \\
\hline Age (mean, median, min-max) & & \multicolumn{2}{|c|}{$71,72,32-93$} \\
\hline \multirow[t]{4}{*}{ ECOG PS } & 0 & 452 & $78.7 \%$ \\
\hline & 1 & 102 & $17.8 \%$ \\
\hline & 2 & 15 & $2.6 \%$ \\
\hline & 3 & 5 & $0.9 \%$ \\
\hline \multirow[t]{2}{*}{ Tumor focality } & Unifocal & 467 & $81.4 \%$ \\
\hline & Multifocal & 107 & $18.6 \%$ \\
\hline \multirow[t]{5}{*}{ pT classification } & pT0/pTis/pTa & 0 & $0.0 \%$ \\
\hline & pT1 & 170 & $29.6 \%$ \\
\hline & pT2 & 161 & $28.0 \%$ \\
\hline & pT3 & 230 & $40.1 \%$ \\
\hline & pT4 & 13 & $2.3 \%$ \\
\hline \multirow[t]{3}{*}{ Grade } & 1 & 38 & $6.6 \%$ \\
\hline & 2 & 269 & $46.9 \%$ \\
\hline & 3 & 267 & $46.5 \%$ \\
\hline \multirow[t]{2}{*}{ LVI } & No & 385 & $67.1 \%$ \\
\hline & Yes & 189 & $32.9 \%$ \\
\hline
\end{tabular}

PS, performance status.

were pT3, and the remaining $4(1.2 \%)$ were pT4. While in the 110 patients with GPS score $2 ; 110(9.1 \%)$ were pT1, $2(1.8 \%)$ were pT2, $92(83.6 \%)$ were pT3, and the remaining $6(5.5 \%)$ were pT4. There were thee times as many cases of pT3 and four time the cases of pT4 in GPS score 2 vs score 0 . The 5 -year and 10 -year CSS rates for 574 patients included in the study were $96 \pm 1 \%$ and $64 \pm$ $3 \%$, respectively. The 5 -year and 10 -year OS rates were 93 $\pm 1 \%$ and $53 \pm 3 \%$, respectively. Kaplan Meier analyses showed that GPS score significantly affected the CSS and OS rates (Figures 1 and 2). The 10-year CSS in patients with GPS0, GPS1, and GPS2 were 69\% (reference), 69\% $(p=0.425)$, and $47 \%(p<0.001)$, respectively (Figure 1$)$. The 10-year OS in patients with GPS0, GPS1, and GPS2 were $63 \%$ (reference), $50 \%(p=0.006)$, and $45 \%(p<$ 0.001 ), respectively (Figure 2).

On univariate analysis, age $(p<0.01)$, grade $(p$ $<0.01)$, LVI $(p<0.01)$, pT classification $(p<0.01)$, tumor focality $(p<0.01)$, and GPS $(p<0.01)$ were associated significantly with overall survival (Table 3 ).
On multivariate analysis, increasing grade, LVI, and pT classification were the major predictors of relative excess risk of death at 10 years (Table 3). When the analysis was stratified based on LVI, we observed a significant association between GPS and risk of death within ten years of diagnosis with negative LVI group (GPS score1: $\mathrm{OR}=1.92,95 \%$ CI $1.18-3.14, p=0.009 /$ GPS score2: OR $=2.05,95 \%$ CI 1.09-3.84, $p=0.03)$. Also, we observed a significant association between GPS score1 and risk of death within ten years of diagnosis with negative LVI group (OR $=1.93,95 \% \mathrm{CI} 1.17-3.17)$, but no association with GPS score $2(\mathrm{OR}=1.11,95 \%$ CI $0.55-2.25, p=0.78)$ after adjustment for gender, age, tumor focality, ECOG PS, grade, and pT stage (not shown). As seen in Table 4, GPS remained the solo factor for prognosis when analyzed with non-pathological clinical factors. The C-index for 10year CSS were 0.51 for age, grade, LVI, pT classification, tumor focality, GPS were, 0.51, 0.66, 0.70, 0.70, 0.54, and 0.58 , respectively (Table 5). C-index of GPS both for CSS and OS were superior to patients' age and tumor focality, 
and comparable to grade (Table 5). CRP, a constituent element of GPS, is one of the most well-known prognostic factors in urothelial carcinomas including bladder cancer and UTUC [20, 21]. Also, concomitant or metachronous bladder cancer is reported to affect the survival of patients with UTUC [22-24]. We further tested the relationship of GPS with CRP and concomitant bladder cancer for the prognostic impact in patient with UTUC. On multivariate analysis adjusted by CRP, concomitant bladder cancer, and GPS (categorized), GPS remained as a prognostic factor $(p=0.034)$ and GPS score 2 showed highest OR for death $(\mathrm{OR}=2.92,95 \%$ CI 0.89-3.01, $p=0.01)$, while CRP $(\mathrm{OR}=1.04,95 \%$ CI $0.51-2.08, p=0.92)$ and concomitant bladder cancer $(\mathrm{OR}=1.49,95 \%$ CI $0.97-2.28, p=0.07)$ didn't reach significant odds (data not shown).

\section{DISCUSSION}

Prognostic inflammatory markers that include cytokines, blood cell composition, and specific proteins have been reported for their value in varying malignancies [25-30]. The relationship between the systemic inflammatory response and nutrition status as an indicator has been previously reported [31-33]. There are papers that investigated the role of GPS in UTUC. Cho et al. investigated the role of GPS in 147 patients with UTUC, with specific interest in bladder recurrence. Multivariate analysis for bladder recurrence after surgery, GPS remained as predictors [34]. Another group investigated the prognostic role of inflammation based biomarkers in 181 patients with UTUC by multivariate analysis and showed that tumor location, pathologic $\mathrm{T}$ stage, lymphovascular invasion, margin status, and albumin level were independent contributors for survival [35]. Given these findings, we further verified the prognostic role of GPS in larger cohort with UTUC. Our results have demonstrated that patients with worse GPS score at baseline had significantly shorter survival compared to patients with favorable GPS as illustrated in the Kaplan-Meier survival curves. These results are consistent with studies in other

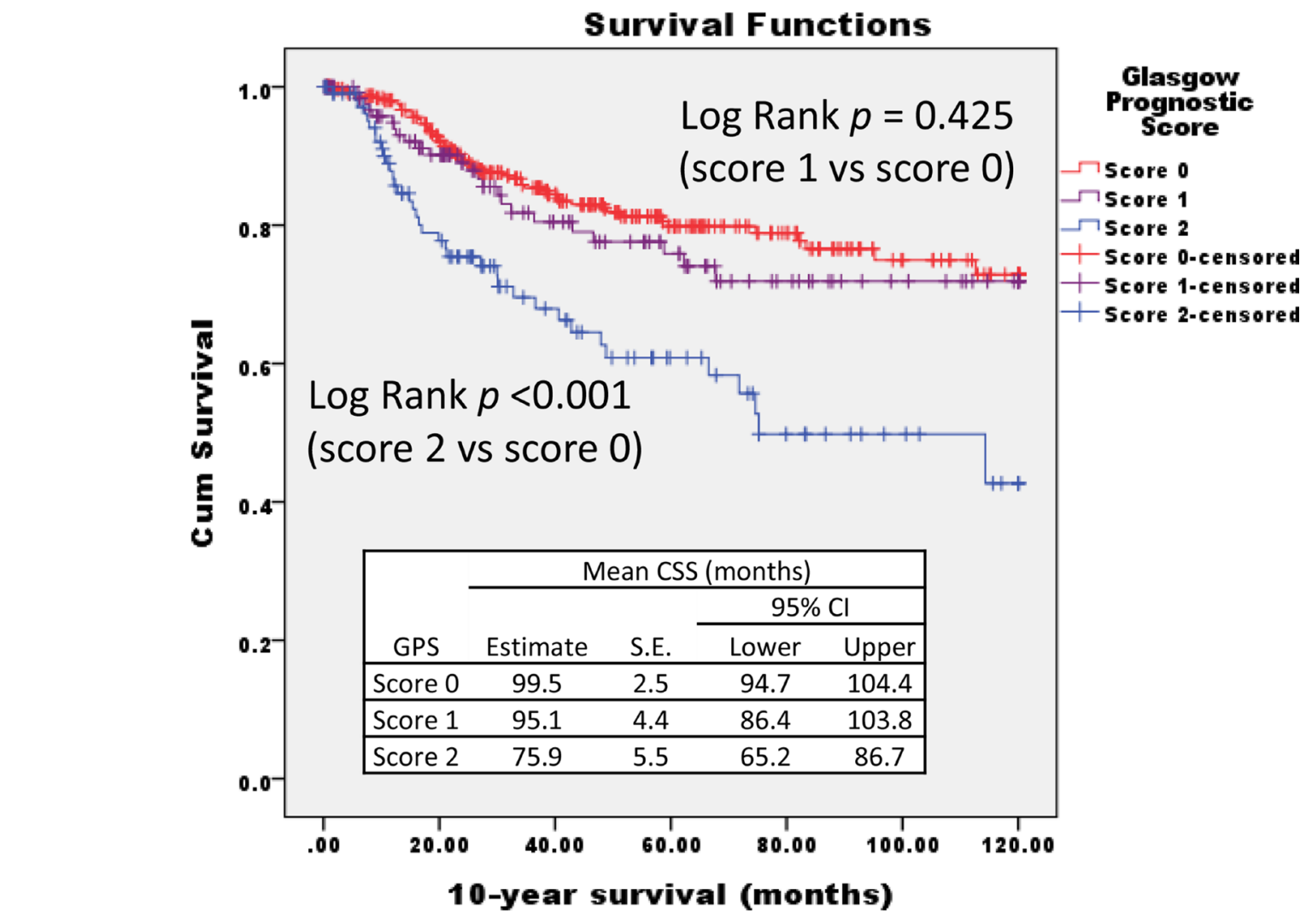

Time interval

$\begin{array}{llllllllllll}10 & 20 & 30 & 40 & 50 & 60 & 70 & 80 & 90 & 100 & 110 & 120\end{array}$

(months)

GPS 0318313311307304303302300296294290169

Numbers at risk

GPS $1124121121121121117114113109107106 \quad 63$

GPS $2105103103102101 \quad 98 \quad 97 \quad 94 \quad 93 \quad 89 \quad 84 \quad 54$

Figure 1: Kaplan-Meier survival curves stratified by Glasgow prognostic score (GPS). The 10-year cancer-specific survival in patients with GPS0, GPS1, and GPS2 are indicated. 


\begin{tabular}{|c|c|c|c|c|c|c|c|c|}
\hline & & \multicolumn{6}{|c|}{ GPS } & \multirow[b]{3}{*}{$p$ value } \\
\hline & & \multicolumn{2}{|c|}{ Score 0} & \multicolumn{2}{|c|}{ Score 1} & \multicolumn{2}{|c|}{ Score 2} & \\
\hline & & Number & $\%$ & Number & $\%$ & Number & $\%$ & \\
\hline \multirow[t]{2}{*}{ Gender } & Male & 232 & $69.9 \%$ & 95 & $72.0 \%$ & 68 & $61.8 \%$ & 0.19 \\
\hline & Female & 100 & $30.1 \%$ & 37 & $28.0 \%$ & 42 & $38.2 \%$ & \\
\hline \multicolumn{2}{|c|}{ Age (mean, median, min-max) } & \multicolumn{2}{|c|}{$70,72,41-92$} & \multicolumn{2}{|c|}{$72,72,46-93$} & \multicolumn{2}{|c|}{$72,72,32-93$} & \\
\hline \multirow[t]{4}{*}{ ECOG PS } & 0 & 269 & $81.0 \%$ & 101 & $76.5 \%$ & 82 & $74.5 \%$ & 0.20 \\
\hline & 1 & 51 & $15.4 \%$ & 28 & $21.2 \%$ & 23 & $20.9 \%$ & \\
\hline & 2 & 11 & $3.3 \%$ & 1 & $0.8 \%$ & 3 & $2.7 \%$ & \\
\hline & 3 & 1 & $0.3 \%$ & 2 & $1.5 \%$ & 2 & $1.8 \%$ & \\
\hline \multirow[t]{2}{*}{ Tumor focality } & Unifocal & 276 & $83.1 \%$ & 104 & $78.8 \%$ & 87 & $79.1 \%$ & 0.44 \\
\hline & Multifocal & 56 & $16.9 \%$ & 28 & $21.2 \%$ & 23 & $20.9 \%$ & \\
\hline \multirow[t]{4}{*}{ pT classification } & pT1 & 136 & $41.0 \%$ & 24 & $18.2 \%$ & 10 & $9.1 \%$ & $<0.01$ \\
\hline & pT2 & 88 & $26.5 \%$ & 71 & $53.8 \%$ & 2 & $1.8 \%$ & \\
\hline & pT3 & 104 & $31.3 \%$ & 34 & $25.8 \%$ & 92 & $83.6 \%$ & \\
\hline & pT4 & 4 & $1.2 \%$ & 3 & $2.3 \%$ & 6 & $5.5 \%$ & \\
\hline \multirow[t]{3}{*}{ Grade } & 1 & 26 & $7.8 \%$ & 8 & $6.1 \%$ & 4 & $3.6 \%$ & $<0.01$ \\
\hline & 2 & 169 & $50.9 \%$ & 66 & $50.0 \%$ & 34 & $30.9 \%$ & \\
\hline & 3 & 137 & $41.3 \%$ & 58 & $43.9 \%$ & 72 & $65.5 \%$ & \\
\hline \multirow[t]{2}{*}{ LVI } & No & 243 & $73.2 \%$ & 95 & $72.0 \%$ & 47 & $42.7 \%$ & $<0.01$ \\
\hline & Yes & 89 & $26.8 \%$ & 37 & $28.0 \%$ & 63 & $57.3 \%$ & \\
\hline
\end{tabular}

GPS, Glasgow Prognostic Score; UTUC, upper tract urothelial carcinoma; PS, performance status; LVI, lymphovascular invasion

malignancies [36-39]. It is of interest to consider how these results might be combined in a clinical context. At present, patients with high risk features including increased $\mathrm{pT}$ stage, high grade, and positive LVI, are offered adjuvant chemotherapy, whereas those patients without high risk features are not. In the present study, among patients with UTUC managed by nephroureterectomy, a high-score GPS indicated a statistically significant poorer prognosis when compared with patients who had a low-score GPS. Such high risk patients may therefore be thought to benefit from adjuvant chemotherapy. The utility of the GPS or modified GPS (mGPS) in predicting the response to chemotherapy is not, to our knowledge, known in UTUC. In contrast, there is evidence that GPS not only identifies those patients who are at an increased risk of recurrent disease in other malignancies [39-46]. Leitch, E.F. et al. showed that TNM stage, monocyte count and mGPS were independently associated with CSS in patients with colorectal cancer [26]. Similarly, Kishiki, T. et al. exhibited that hemoglobin, adjuvant chemotherapy, and mGPS were significant predictive factors for postoperative mortality in patients with incurable stage IV colorectal cancer
[43]. Jiang, A.G. et al. found GPS is more accurate than prognostic index (PI) in predicting prognosis for patients with advanced non-small cell lung cancer (NSCLC), with the area under the receiver operating characteristic curve for GPS predicting 1-year disease free survival (DFS) being 0.62 , and the area under curve for PI predicting 1 -year DFS being 0.57 [47]. Linton, A. et al. investigated the baseline mGPS and NLR in a prospective cohort of chemotherapy-naive patients with metastatic castrationresistant prostate cancer (mCRPC) who received docetaxel and prednisone [42]. The TNM staging system provides the reliable information on patients' prognosis and aids in the discrimination of patients with early stage disease from those with advanced stage disease. However, it is less accurate for predicting the prognosis of patients with an intermediate extent of tumor invasion. In hour cohort, an increased GPS was associated with increased $\mathrm{pT}$ classification $(p<0.001)$, grade $(p<0.001)$, and LVI $(p<$ $0.001)$ but there was no association with gender $(p=0.192)$, ECOG PS $(p=0.204)$, and tumor focality $(p=0.441)$. Moug, S.J. et al. compared two scoring systems which have been proposed in colorectal cancer: the pathologically 
Table 3: Cox regression analysis for 10 -year OS

\begin{tabular}{|c|c|c|c|c|c|c|c|c|}
\hline & \multicolumn{4}{|c|}{ Univariate } & \multicolumn{4}{|c|}{ Multivariate } \\
\hline & \multirow[b]{2}{*}{$p$ value } & \multirow[b]{2}{*}{ OR } & \multicolumn{2}{|c|}{$95 \%$ CI } & \multirow[b]{2}{*}{$p$ value } & \multirow[b]{2}{*}{ OR } & \multicolumn{2}{|c|}{$95 \% \mathrm{CI}$} \\
\hline & & & Lower & Upper & & & Lower & Upper \\
\hline Gender & 0.56 & 1.10 & 0.80 & 1.52 & 0.77 & 0.94 & 0.64 & 1.40 \\
\hline Age & $<0.01$ & 1.03 & 1.02 & 1.05 & 0.17 & 1.02 & 0.99 & 1.04 \\
\hline ECOG PS & 0.07 & 1.26 & 0.98 & 1.62 & 0.60 & 1.09 & 0.78 & 1.53 \\
\hline Grade & $<0.01$ & 1.92 & 1.46 & 2.53 & 0.01 & 1.68 & 1.14 & 2.47 \\
\hline LVI & $<0.01$ & 3.54 & 2.60 & 4.81 & $<0.01$ & 2.90 & 1.86 & 4.54 \\
\hline pT classification & $<0.01$ & 1.94 & 1.60 & 2.34 & $<0.01$ & 1.73 & 1.29 & 2.31 \\
\hline Tumor focality & $<0.01$ & 1.70 & 1.20 & 2.41 & 0.12 & 1.40 & 0.92 & 2.14 \\
\hline GPS & $<0.01$ & 1.57 & 1.31 & 1.88 & 0.53 & 1.07 & 0.86 & 1.34 \\
\hline
\end{tabular}

OS, overall survival; CI, confidence interval; PS, performance status; LVI, lymphovascular invasion ; GPS, Glasgow Prognostic Score.

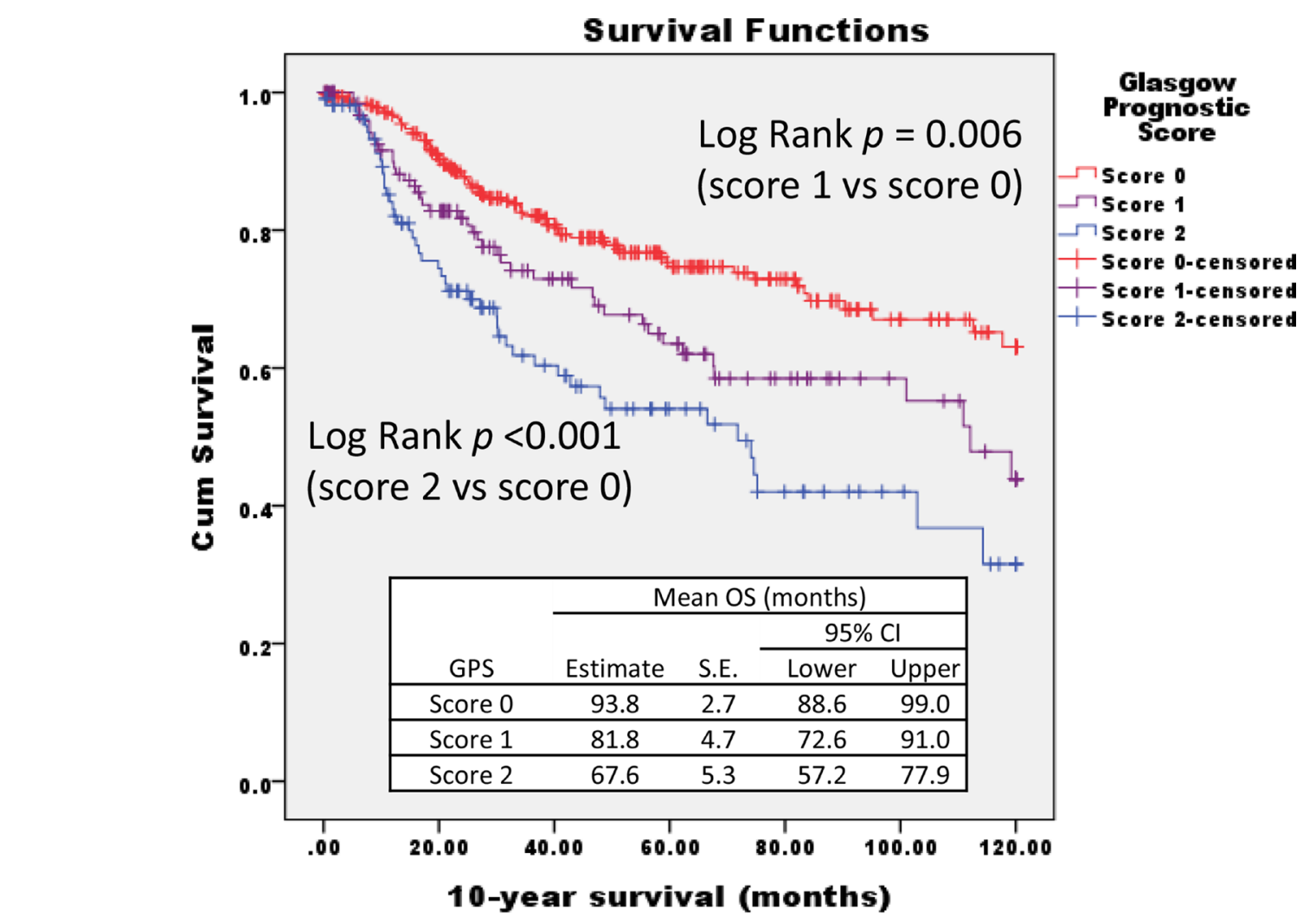

\begin{tabular}{|c|c|c|c|c|c|c|c|c|c|c|c|c|c|}
\hline $\begin{array}{l}\text { Time interval } \\
\text { (months) }\end{array}$ & & 10 & 20 & 30 & 40 & 50 & 60 & 70 & 80 & 90 & 100 & 110 & 120 \\
\hline & urs & 318 & 313 & 311 & 307 & 304 & 303 & 303 & 300 & 296 & 294 & 290 & 176 \\
\hline isk & GPS 1 & 124 & 121 & 121 & 121 & 121 & 118 & 114 & 113 & 110 & 107 & 106 & 70 \\
\hline & GPS 2 & 105 & 103 & 103 & 102 & 101 & 98 & 97 & 94 & 93 & 90 & 84 & 57 \\
\hline
\end{tabular}

Figure 2: Kaplan-Meier survival curves stratified by glasgow prognostic score (GPS). The 10-year overall survival in patients with GPS0, GPS1, and GPS2 are indicated. 
Table 4: Cox multivariate regression analysis for 10-year OS

\begin{tabular}{lcccc}
\hline & & & \multicolumn{2}{c}{$\mathbf{9 5 \%}$ CI } \\
\cline { 3 - 4 } Gender & $\boldsymbol{p}$ value & OR & Lower & Upper \\
Age & 0.422 & 1.171 & 0.797 & 1.722 \\
ECOG PS & 0.107 & 1.017 & 0.996 & 1.038 \\
Tumor focality & 0.901 & 1.022 & 0.721 & 1.449 \\
Glasgow Prognostic Score & 0.058 & 1.504 & 0.986 & 2.294 \\
\hline
\end{tabular}

OS, overall survival; CI, confidence interval; PS, performance status.

Table 5: Model accuracy for 10-year CSS and OS

\begin{tabular}{|c|c|c|c|c|c|c|c|c|c|c|}
\hline & \multicolumn{5}{|c|}{ CSS } & \multicolumn{5}{|c|}{ OS } \\
\hline & \multirow[b]{2}{*}{ C-index } & \multirow[b]{2}{*}{ SE } & \multirow[b]{2}{*}{$p$} & \multicolumn{2}{|c|}{$95 \%$ CI } & \multirow[b]{2}{*}{ C-index } & \multirow[b]{2}{*}{ SE } & \multirow[b]{2}{*}{$p$} & \multicolumn{2}{|c|}{$95 \% \mathrm{CI}$} \\
\hline & & & & Lower & Upper & & & & Lower & Upper \\
\hline$\overline{\text { Age }}$ & 0.51 & 0.03 & 0.72 & 0.45 & 0.57 & 0.55 & 0.03 & 0.09 & 0.50 & 0.60 \\
\hline Grade & 0.66 & 0.03 & $<0.01$ & 0.60 & 0.71 & 0.60 & 0.03 & $<0.01$ & 0.55 & 0.65 \\
\hline LVI & 0.70 & 0.03 & $<0.01$ & 0.65 & 0.76 & 0.64 & 0.03 & $<0.01$ & 0.59 & 0.69 \\
\hline pT classification & 0.70 & 0.03 & $<0.01$ & 0.65 & 0.75 & 0.64 & 0.03 & $<0.01$ & 0.59 & 0.69 \\
\hline Tumor focality & 0.54 & 0.03 & 0.14 & 0.48 & 0.60 & 0.55 & 0.03 & 0.06 & 0.50 & 0.60 \\
\hline GPS & 0.58 & 0.03 & $<0.01$ & 0.52 & 0.65 & 0.60 & 0.03 & $<0.01$ & 0.55 & 0.65 \\
\hline
\end{tabular}

CSS, cancer specific survival; OS, overall survival; CI, confidence interval; LVI, lymphovascular invasion ; GPS, Glasgow Prognostic Score

based positive lymph node ratio (pLNR) and inflammation based mGPS with the TNM staging system in terms of cancer survival [48]. On multivariate model, $\mathrm{N}$ category and tumour stage (I-III) were removed from the model, leaving $\mathrm{pLNR}$ and mGPS as independent predictors of OS with hazard ratio of 1.51 [48]. Zhang, P et al. investigated the prognostic value of mGPS in patients with inoperable thoracic esophageal squamous cell carcinoma undergoing chemoradiotherapy [49]. They found T stage, M stage and mGPS were independent prognostic indicators for OS, and T stage, M stage, mGPS and platelet count were independent prognostic indicators for PFS, concluding that mGPS can be used in combination with conventional TNM staging to predict survival in patients with squamous cell carcinoma undergoing chemoradiotherapy [49]. The present study has limitations that are typical to the study based on retrospective database, which include the risk of unidentified confounding factors, missing data, and the potential for miscoding of data. Additionally, the present cohort does not describe some important pathologic factors such as updated grading system, perineurial tumor invasion, the status of previous or concomitant urinary bladder lesions, the histological patterns, mitotic activity, and so on. Even with these limitations, our data present the new characterization of UTUC and outcomes.
Therefore, on the basis of the available evidence, the GPS/mGPS may potentially be included, together with the other known factors, in the post-operative follow-up of patients with primary operable UTUC and the stratification of patients entering treatment of adjuvant chemotherapy.

\section{CONCLUSIONS}

The present study is the first to demonstrate that malnutrition, as determined by GPS was significant independent predictors of survival in patients with UTUC and had a strong association with LVI. Nutritional and inflammatory statuses are modifiable factors which may be favorably altered by early nutritional and antiinflammatory interventions, thereby resulting in a significant improvement in survival. These promising and rather simple interventions need to be investigated further to fully understand their impact on the clinical outcomes of patients with UTUC.

\section{CONFLICTS OF INTEREST}

None. 


\section{REFERENCES}

1. Smith ND. Management of upper tract urothelial carcinoma. Adv Urol. 2009: 492462. https://doi. org/10.1155/2009/492462.

2. Waldert M, Karakiewicz PI, Raman JD, Remzi M, Isbarn H, Lotan Y, Capitanio U, Bensalah K, Marberger MJ, Shariat SF. A delay in radical nephroureterectomy can lead to upstaging. BJU Int. 2010; 105:812-7. https://doi. org/10.1111/j.1464-410X.2009.08821.x.

3. Zigeuner R, Shariat SF, Margulis V, Karakiewicz PI, Roscigno M, Weizer A, Kikuchi E, Remzi M, Raman JD, Bolenz C, Bensalah K, Capitanio U, Koppie TM, et al. Tumour necrosis is an indicator of aggressive biology in patients with urothelial carcinoma of the upper urinary tract. Eur Urol. 2010; 57:575-81. https://doi.org/10.1016/j. eururo.2009.11.035.

4. Kauffman EC, Raman JD. Bladder cancer following upper tract urothelial carcinoma. Expert Rev Anticancer Ther. 2008; 8:75-85. https://doi.org/10.1586/14737140.8.1.75.

5. Chromecki TF, Cha EK, Fajkovic H, Margulis V, Novara G, Scherr DS, Lotan Y, Raman JD, Kassouf W, Bensalah K, Weizer A, Kikuchi E, Roscigno M, et al. The impact of tumor multifocality on outcomes in patients treated with radical nephroureterectomy. Eur Urol. 2012; 61:245-53. https://doi.org/10.1016/j.eururo.2011.09.017.

6. Jankovic Velickovic L, Dolicanin Z, Stefanovic V. Endemic nephropathy and upper urothelial carcinoma - new insights in molecular biology. Prilozi. 2014; 35:57-64.

7. Dalpiaz O, Pichler M, Mannweiler S, Martin Hernandez JM, Stojakovic T, Pummer K, Zigeuner R, Hutterer GC. Validation of the pretreatment derived neutrophillymphocyte ratio as a prognostic factor in a European cohort of patients with upper tract urothelial carcinoma. Br J Cancer. 2014; 110:2531-6. https://doi.org/10.1038/ bjc.2014.180.

8. Tanaka N, Kikuchi E, Kanao K, Matsumoto K, Shirotake S, Miyazaki Y, Kobayashi H, Kaneko G, Hagiwara M, Ide H, Obata J, Hoshino K, Hayakawa N, et al. A MultiInstitutional Validation of the Prognostic Value of the Neutrophil-to-Lymphocyte Ratio for Upper Tract Urothelial Carcinoma Treated with Radical Nephroureterectomy. Ann Surg Oncol. 2014; 21:4041-8. https://doi.org/10.1245/ s10434-014-3830-3.

9. Gakis G, Fritsche HM, Hassan F, Kluth L, Miller F, Soave A, Otto W, Schwentner C, Todenhofer T, Dahlem R, Burger M, Fisch M, Stenzl A, et al. Prognostic relevance of postoperative platelet count in upper tract urothelial carcinoma after radical nephroureterectomy. Eur J Cancer. 2014; 50:2583-91. https://doi.org/10.1016/j. ejca.2014.07.003.

10. Tomita M, Ayabe T, Chosa E, Nakamura K. Prognostic significance of pre- and postoperative glasgow prognostic score for patients with non-small cell lung cancer. Anticancer Res. 2014; 34:3137-40.
11. Takeno S, Hashimoto T, Shibata R, Maki K, Shiwaku H, Yamana I, Yamashita R, Yamashita Y. The high-sensitivity modified glasgow prognostic score is superior to the modified glasgow prognostic score as a prognostic predictor in patients with resectable gastric cancer. Oncology. 2014; 87:205-14. https://doi.org/10.1159/000362601.

12. Nakagawa K, Tanaka K, Nojiri K, Kumamoto T, Takeda K, Ueda M, Endo I. The modified Glasgow prognostic score as a predictor of survival after hepatectomy for colorectal liver metastases. Ann Surg Oncol. 2014; 21:1711-8. https://doi. org/10.1245/s10434-013-3342-6.

13. Matsuda S, Takeuchi H, Kawakubo H, Fukuda K, Nakamura R, Takahashi T, Wada N, Saikawa Y, Omori T, Kitagawa Y. Cumulative Prognostic Scores Based on Plasma Fibrinogen and Serum Albumin Levels in Esophageal Cancer Patients Treated with Transthoracic Esophagectomy: Comparison with the Glasgow Prognostic Score. Ann Surg Oncol. 2014. https://doi.org/10.1245/s10434-014-3857-5.

14. Tanaka N, Kikuchi E, Shirotake S, Kanao K, Matsumoto K, Kobayashi H, Miyazaki Y, Ide H, Obata J, Hoshino $\mathrm{K}$, Hayakawa N, Ito Y, Kosaka T, et al. The predictive value of C-reactive protein for prognosis in patients with upper tract urothelial carcinoma treated with radical nephroureterectomy: a multi-institutional study. Eur Urol. 2014; 65:227-34. https://doi.org/10.1016/j. eururo.2012.11.050.

15. Fujita K, Uemura M, Yamamoto $Y$, Tanigawa G, Nakata W, Sato M, Nagahara A, Kiuchi H, Nakai Y, Matsumiya K, Yamaguchi S, Nonomura N. Preoperative risk stratification for cancer-specific survival of patients with upper urinary tract urothelial carcinoma treated by nephroureterectomy. Int J Clin Oncol. 2014. https://doi.org/10.1007/s10147-0140695-1.

16. Obata J, Kikuchi E, Tanaka N, Matsumoto K, Hayakawa N, Ide H, Miyajima A, Nakagawa K, Oya M. C-reactive protein: a biomarker of survival in patients with localized upper tract urothelial carcinoma treated with radical nephroureterectomy. Urol Oncol. 2013; 31:1725-30. https:// doi.org/10.1016/j.urolonc.2012.05.008.

17. Aziz A, Rink M, Gakis G, Kluth LA, Dechet C, Miller F, Otto W, Gierth M, Denzinger S, Schwentner C, Stenzl A, Fisch M, Burger M, et al. Preoperative C-reactive protein in the serum: a prognostic biomarker for upper urinary tract urothelial carcinoma treated with radical nephroureterectomy. Urol Int. 2014; 93:352-60. https://doi. org/10.1159/000362248.

18. Sakano S, Matsuyama H, Kamiryo Y, Hayashida S, Yamamoto N, Kaneda Y, Nasu T, Baba Y, Shimabukuro T, Suga A, Yamamoto M, Aoki A, Takai K, et al. Impact of variant histology on disease aggressiveness and outcome after nephroureterectomy in Japanese patients with upper tract urothelial carcinoma. Int J Clin Oncol. 2014. https:// doi.org/10.1007/s10147-014-0721-3.

19. Inamoto T, Komura K, Watsuji T, Azuma H. Specific body mass index cut-off value in relation to survival of patients 
with upper urinary tract urothelial carcinomas. Int J Clin Oncol. 2012; 17:256-62. https://doi.org/10.1007/s10147011-0284-5.

20. Luo Y, Fu SJ, She DL, Xiong HU, Yang LI. Preoperative C-reactive protein as a prognostic predictor for upper tract urothelial carcinoma: A systematic review and metaanalysis. Mol Clin Oncol. 2015; 3:924-8. https://doi. org/10.3892/mco.2015.553.

21. Morizane S, Yumioka T, Yamaguchi N, Masago T, Honda M, Sejima T, Takenaka A. Risk stratification model, including preoperative serum $\mathrm{C}$-reactive protein and estimated glomerular filtration rate levels, in patients with upper urinary tract urothelial carcinoma undergoing radical nephroureterectomy. Int Urol Nephrol. 2015; 47:1335-41. https://doi.org/10.1007/s11255-015-1033-x.

22. Feng C, Wang L, Ding G, Ding Q, Zhou Z, Jiang H, Wu $Z$. Predictive value of clinicopathological markers for the metachronous bladder cancer and prognosis of upper tract urothelial carcinoma. Sci Rep. 2014; 4:4015. https://doi. org/10.1038/srep04015.

23. Fang D, Zhang L, Li X, Yu W, Singla N, Zhao G, Xiong G, Song Y, He Q, He Z, Zhou L. Presence of Concomitant Non-muscle-invasive Bladder Cancer in Chinese Patients with Upper Tract Urothelial Carcinoma: Risk Factors, Characteristics, and Predictive Value. Ann Surg Oncol. 2015; 22:2789-98. https://doi.org/10.1245/s10434-0144302-5.

24. Kim BW, Ha YS, Lee JN, Kim HT, Kim TH, Lee JK, Byun SS, Choi YD, Kang HW, Yun SJ, Kim WJ, Kwon YS, Kwon TG. Effects of Previous or Synchronous Non-Muscle Invasive Bladder Cancer on Clinical Results after Radical Nephroureterectomy for Upper Tract Urothelial Carcinoma: A Multi-Institutional Study. Urol J. 2015; 12:2233-9.

25. Leung EY, Roxburgh CS, Talwar D, O'Reilly DS, McKee RF, Horgan PG, McMillan DC. The relationships between plasma and red cell vitamin B2 and B6 concentrations and the systemic and local inflammatory responses in patients with colorectal cancer. Nutr Cancer. 2012; 64:515-20. https://doi.org/10.1080/01635581.2012.661512.

26. Leitch EF, Chakrabarti M, Crozier JE, McKee RF, Anderson JH, Horgan PG, McMillan DC. Comparison of the prognostic value of selected markers of the systemic inflammatory response in patients with colorectal cancer. Br J Cancer. 2007; 97:1266-70. https://doi.org/10.1038/ sj.bjc. 6604027.

27. Inoue $Y$, Iwata T, Okugawa Y, Kawamoto A, Hiro J, Toiyama Y, Tanaka K, Uchida K, Mohri Y, Miki C, Kusunoki M. Prognostic significance of a systemic inflammatory response in patients undergoing multimodality therapy for advanced colorectal cancer. Oncology. 2013; 84:100-7. https://doi.org/10.1159/000343822.

28. Hamilton TD, Leugner D, Kopciuk K, Dixon E, Sutherland $\mathrm{FR}$, Bathe OF. Identification of prognostic inflammatory factors in colorectal liver metastases. BMC Cancer. 2014; 14:542. https://doi.org/10.1186/1471-2407-14-542.
29. Guthrie GJ, Roxburgh CS, Richards CH, Horgan PG, McMillan DC. Circulating IL-6 concentrations link tumour necrosis and systemic and local inflammatory responses in patients undergoing resection for colorectal cancer. Br J Cancer. 2013; 109:131-7. https://doi.org/10.1038/ bjc.2013.291.

30. Ahmad J, Grimes N, Farid S, Morris-Stiff G. Inflammatory response related scoring systems in assessing the prognosis of patients with pancreatic ductal adenocarcinoma: a systematic review. Hepatobiliary Pancreat Dis Int. 2014; $13: 474-81$

31. Li QQ, Lu ZH, Yang L, Lu M, Zhang XT, Li J, Zhou J, Wang XC, Gong JF, Gao J, Li J, Li Y, Shen L. Neutrophil count and the inflammation-based glasgow prognostic score predict survival in patients with advanced gastric cancer receiving first-line chemotherapy. Asian Pac J Cancer Prev. 2014; 15:945-50.

32. Cheng SP, Liu CL, Liu TP, Hsu YC, Lee JJ. Association between parathyroid hormone levels and inflammatory markers among US adults. Mediators Inflamm. 2014; 2014:709024. https://doi.org/10.1155/2014/709024.

33. Wang DS, Luo HY, Qiu MZ, Wang ZQ, Zhang DS, Wang $\mathrm{FH}, \mathrm{Li} \mathrm{YH}, \mathrm{Xu} \mathrm{RH}$. Comparison of the prognostic values of various inflammation based factors in patients with pancreatic cancer. Med Oncol. 2012; 29:3092-100. https:// doi.org/10.1007/s12032-012-0226-8.

34. Cho YH, Seo YH, Chung SJ, Hwang I, Yu HS, Kim SO, Jung SI, Kang TW, Kwon DD, Park K, Hwang JE, Heo $\mathrm{SH}$, Kim GS, et al. Predictors of intravesical recurrence after radical nephroureterectomy for upper urinary tract urothelial carcinoma: an inflammation-based prognostic score. Korean J Urol. 2014; 55:453-9. https://doi. org/10.4111/kju.2014.55.7.453.

35. Ku JH, Kim M, Choi WS, Kwak C, Kim HH. Preoperative serum albumin as a prognostic factor in patients with upper urinary tract urothelial carcinoma. Int Braz J Urol. 2014; 40:753-62. https://doi.org/10.1590/S1677-5538. IBJU.2014.06.06.

36. Zhou T, Hong S, Hu Z, Hou X, Huang Y, Zhao H, Liang W, Zhao Y, Fang W, Wu X, Qin T, Zhang L. A systemic inflammation-based prognostic scores (mGPS) predicts overall survival of patients with small-cell lung cancer. Tumour Biol. 2014. https://doi.org/10.1007/s13277-0142623-4.

37. Ikuta Y, Takamori H, Sakamoto Y, Hashimoto D, Chikamoto A, Kuroki H, Sakata K, Sakamoto K, Hayashi H, Imai K, Nitta H, Hirota M, Kanemitsu K, et al. The modified Glasgow Prognostic Score (mGPS) is a good predictor of indication for palliative bypass surgery in patients with unresectable pancreatic and biliary cancers. Int J Clin Oncol. 2014; 19:629-33. https://doi.org/10.1007/s10147013-0613-y.

38. Iwasaki Y, Ishizuka M, Kato M, Kita J, Shimoda M, Kubota $\mathrm{K}$. Usefulness of an inflammation-based prognostic score (mGPS) for predicting survival in patients with unresectable 
malignant biliary obstruction. World J Surg. 2013; 37:22228. https://doi.org/10.1007/s00268-013-2075-9.

39. Gioulbasanis I, Pallis A, Vlachostergios PJ, Xyrafas A, Giannousi Z, Perdikouri IE, Makridou M, Kakalou D, Georgoulias V. The Glasgow Prognostic Score (GPS) predicts toxicity and efficacy in platinum-based treated patients with metastatic lung cancer. Lung Cancer. 2012; 77:383-8. https://doi.org/10.1016/j.lungcan.2012.04.008.

40. Mimatsu K, Oida T, Fukino N, Kano H, Kawasaki A, Kida $\mathrm{K}$, Kuboi Y, Amano S. Glasgow prognostic score is a useful predictive factor of outcome after palliative gastrectomy for stage IV gastric cancer. Anticancer Res. 2014; 34:3131-6.

41. Maillet M, Dreanic J, Dhooge M, Mir O, Brezault C, Goldwasser F, Chaussade S, Coriat R. The predictive and prognostic value of the Glasgow Prognostic Score in metastatic colorectal carcinoma patients receiving bevacizumab. Anticancer Drugs. 2014; 25:1215-9. https:// doi.org/10.1097/CAD.0000000000000129.

42. Linton A, Pond G, Clarke S, Vardy J, Galsky M, Sonpavde G. Glasgow prognostic score as a prognostic factor in metastatic castration-resistant prostate cancer treated with docetaxel-based chemotherapy. Clin Genitourin Cancer. 2013; 11:423-30. https://doi.org/10.1016/j. clgc.2013.04.020.

43. Kishiki T, Masaki T, Matsuoka H, Kobayashi T, Suzuki Y, Abe N, Mori T, Sugiyama M. Modified Glasgow prognostic score in patients with incurable stage IV colorectal cancer. Am J Surg. 2013; 206:234-40. https://doi.org/10.1016/j. amjsurg.2012.07.051.

44. Jamieson NB, Denley SM, Logue J, MacKenzie DJ, Foulis AK, Dickson EJ, Imrie CW, Carter R, McKay CJ, McMillan DC. A prospective comparison of the prognostic value of tumor- and patient-related factors in patients undergoing potentially curative surgery for pancreatic ductal adenocarcinoma. Ann Surg Oncol. 2011; 18:231828. https://doi.org/10.1245/s10434-011-1560-3.

45. Iwaku A, Kinoshita A, Onoda H, Fushiya N, Nishino H, Matsushima M, Tajiri H. The Glasgow Prognostic Score accurately predicts survival in patients with biliary tract cancer not indicated for surgical resection. Med Oncol. 2014; 31:787. https://doi.org/10.1007/s12032-013-0787-1.

46. Furukawa K, Shiba H, Haruki K, Fujiwara Y, Iida T, Mitsuyama Y, Ogawa M, Ishida Y, Misawa T, Yanaga K. The Glasgow prognostic score is valuable for colorectal cancer with both synchronous and metachronous unresectable liver metastases. Oncol Lett. 2012; 4:324-8. https://doi.org/10.3892/ol.2012.722.

47. Jiang AG, Chen HL, Lu HY. Comparison of Glasgow prognostic score and prognostic index in patients with advanced non-small cell lung cancer. J Cancer Res Clin Oncol. 2014. https://doi.org/10.1007/s00432-014-1839-4.

48. Moug SJ, McColl G, Lloyd SM, Wilson G, Saldanha JD, Diament RH. Comparison of positive lymph node ratio with an inflammation-based prognostic score in colorectal cancer. Br J Surg. 2011; 98:282-6. https://doi.org/10.1002/ bjs. 7294 .

49. Zhang P, Xi M, Li QQ, He LR, Liu SL, Zhao L, Shen JX, Liu MZ. The modified glasgow prognostic score is an independent prognostic factor in patients with inoperable thoracic esophageal squamous cell carcinoma undergoing chemoradiotherapy. J Cancer. 2014; 5:689-95. https://doi. org/10.7150/jca.9569. 